\title{
The Molecular Biology of Human T Cell Leukemia Virus and its Roles in Leukemogenesis of Adult T Cell Leukemia *
}

\author{
M. Yoshida and M. Seiki
}

\section{A. Introduction}

Adult $\mathrm{T}$ cell leukemia (ATL) is a unique $\mathrm{T}$ cell malignancy proposed by Takatsuki and his colleagues [1]; it is endemic in the south-western part of Japan [1,2] and has been found in the Caribbean [3]. Human T cell leukemia virus (HTLV) was isolated by Gallo and his colleagues [4] from a patient with cutaneous $T$ cell lymphoma, and subsequently adult $\mathrm{T}$ cell leukemia virus (ATLV) was isolated by us [5]. We have molecularly cloned the provirus genome [6] and determined the total nucleotide sequence of the ATLV provirus genome [7]. Based on the structural analysis, we recently reported that ATLV and HTLV type I are the same virus species [8,9]. After

* Department of Viral Oncology, Cancer Institute, Kami-Ikebukuro, Toshima-ku, Tokyo 170, Japan these characterizations, we use the term HTLV-I for the virus previously reported as ATLV. HTLV is exogenous for humans [5, 10], distinct from known animal retroviruses $[6,7]$, and is closely associated with ATL $[2,5,11]$. In this chapter, we summarize our studies on the mechanism of leukemogenesis of ATL and identification of the viral proteins.

\section{B. HTLV Plays Causative Roles in ATL Development}

Structural analysis of HTLV genome [7] showed that it contains gag, pol, env, and an extra sequence of $p X$ which can code for some proteins (Fig. 1). Since none of them showed sequence homology with uninfected human DNA, it was concluded that HTLV has no typical onc gene derived from a cellular sequence [7]. Thus, the following question was raised: is HTLV involved directly in leukemogenesis of ATL?

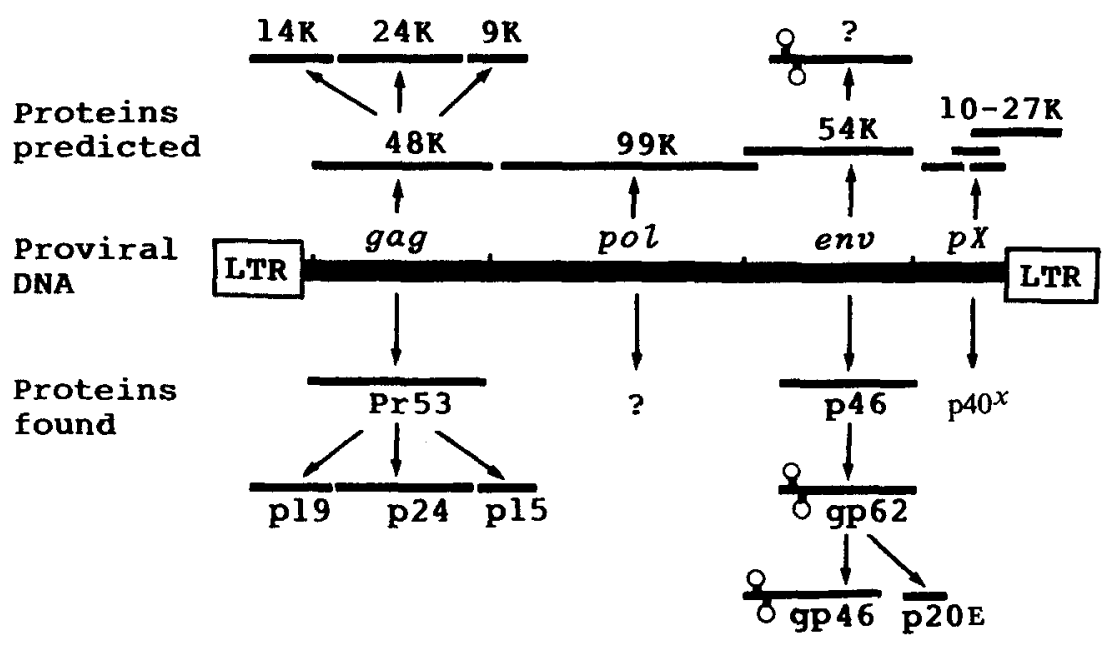

Fig. 1. Summary of provirus genome and proteins of HTLV. The thick bar in the middle represents the provirus genome of HTLV-I and boxes at the ends are LTR. Proteins above the genome are predicted from DNA sequences and those below the genome have actually been identified in HTLVinfected cells 


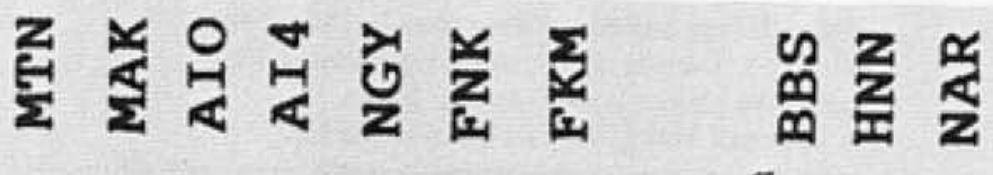

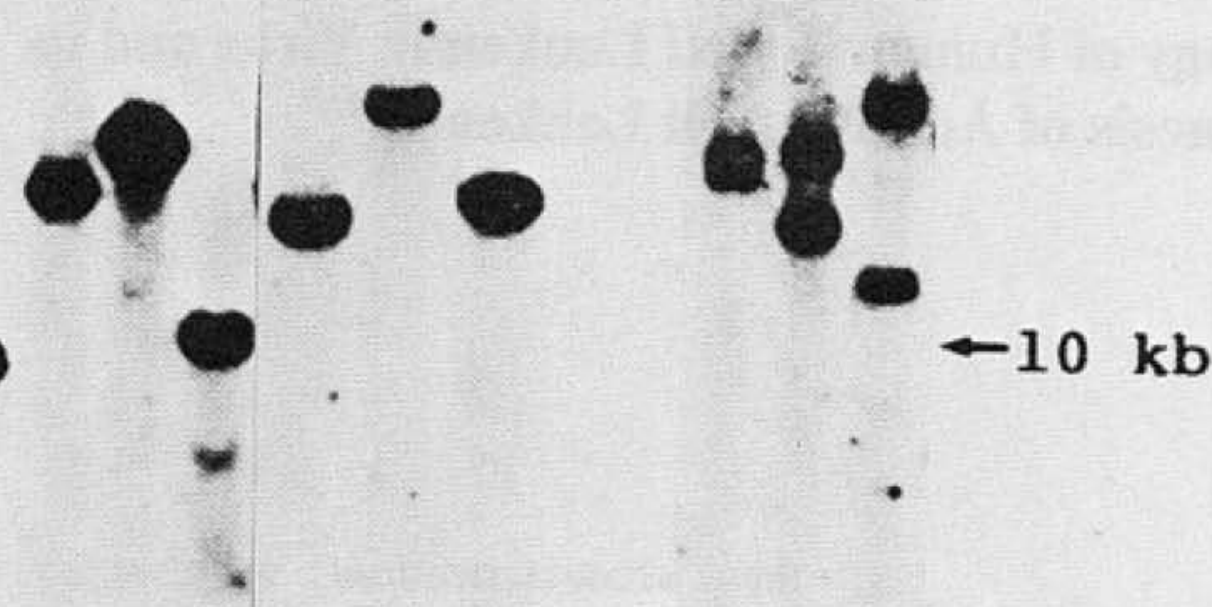

Fig. 2. Detection of HTLV provirus sequences in fresh leukemic cell DNA. Lymphocyte DNA samples from ATL patients were digested with EcoRI, which does not cleave the provirus sequence, and subjected to blotting analysis. ${ }^{32} \mathrm{P}-\mathrm{la}-$ beled DNA of cloned HTLV-I was used as a representative probe in this analysis
To solve this question, we surveyed the provirus integration in fresh tumor cells of 122 cases of ATL. Only fresh tumor cells were used in this study. Cellular DNA isolated from fresh lymphocytes was digested with EcoRI, which does not cleave the proviral genome, and analyzed by the blotting procedure. By this assay, the provirus sequence integrated monoclonally was detected as a discrete band. All 122 patients with typical ATL were infected with HTLV and the provirus sequences were detected as one or two discrete bands as shown in Fig. 2 [12]. These results clearly indicate that the leukemic cells were monoclonal, originating from a single cell infected with HTLV, because integration of HTLV genome in nonleukemic cell DNA was random [13, 14]. The monoclonal expansion of infected cells as tumor cells in all 122 cases strongly suggests that HTLV directly infects the target cell which becomes leukemic, thus implying that HTLV has causative roles in ATL development [12, 13]. If viral involvement was indirect, for example, mediated by one or more factors released by infected cells, some cases should have leukemic cells in which the provirus genome is absent or is integrated at multiple sites.

\section{No Specific Integration Site in Leukemic Cell DNA}

As described, HTLV plays causative roles in ATL development $[12,13]$, although the virus has no typical onc gene [7]. Consequently, one of the most probable mechanisms of ATL leukemogenesis was insertional mutagenesis in which the proviruses are integrated into a few specific loci on the chromosomal DNA and then activate an adjacent cellular onc gene [15].

In order to test this possibility, cellular sequences of fresh leukemic cells of a patient which were flanked to the integrated provirus were cloned and used as probes to detect DNA rearrangements induced by provirus integration at the same locus in other patients. Two sets of probes were isolated from independent patients and each set of the probes could detect an approximately 30 kilobases region of cellular DNA. These probes detected rearranged DNA fragments in the control DNA from which the probes were isolated, but did not detect such rearranged fragments in the other 35 ATL patients [16]. These observations indicate that HTLV has no common site for integration into leukemic cell DNA.

We further analyzed the specificity of provirus integration at the chromosomal 


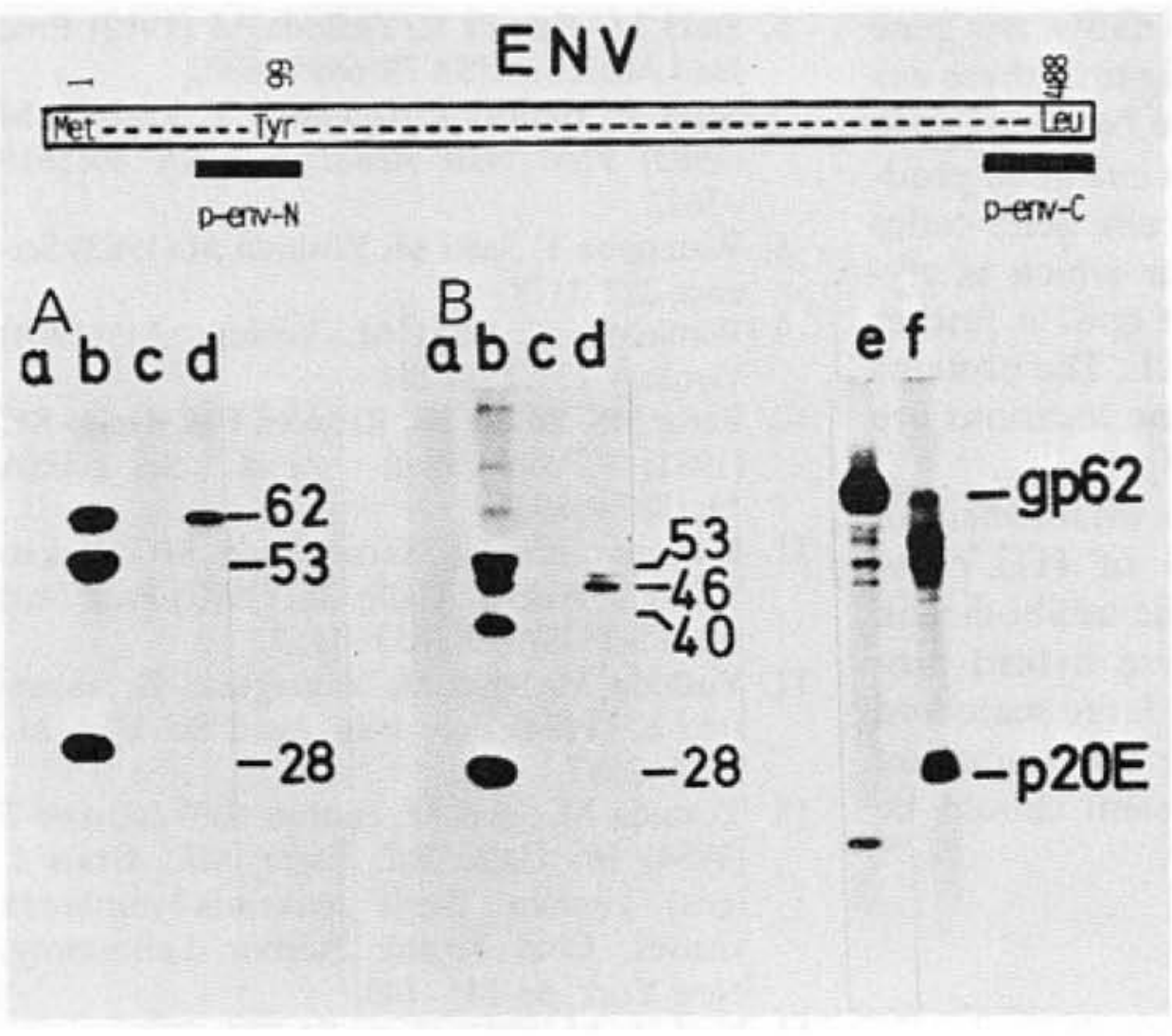

Fig. 3. Identification of env gene products. Decapeptide of the $\mathrm{COOH}$ terminus of the predicted $e n v$ polypeptide (top) was synthesized and antiserum was prepared in a rabbit. MT-2 cells were labeled with cysteine ${ }^{35} \mathrm{~S}$ for $1 \mathrm{~h}$ with $(B)$ or without $(A)$ tunicamycin treatment and extracts were treated with: normal human serum (lane a); serum from an ATL patient (lane b); normal rabbit serum (lane c); and anti-env-C peptide (lane d). Pulselabeled MT-2 cells (lane e) were chased with excess cold cysteine (lane f) and both cell extracts were treated with anti-env-C peptide level by using the human $x$ mouse somatic cell hybrid strategy. The hybrid cells were analyzed for two probes isolated from cellular flanking sequences as described and it was found that one probe cosegregated with chromosome 7 and the other cosegregated with chromosome 17 [16]. Thus, the absence of a common integration site for HTLV was confirmed at the chromosomal level. These results do not support the simple activation of a specific cellular onc gene by HTLV LTR.

\section{Identification and Characterization of $e n v$ Gene Products}

The absence of a common integration site in primary tumor cells [16] does not support a cis-acting function of the integrated proviruses. Thus, proteins coded by HTLV genome are suspected to be involved in ATL development as trans-acting factors. The identification and characterization of the viral proteins are also important to establish the systems for diagnosis and prevention of HTLV infection.

Monospecific antiserum against the synthetic peptide which is the $\mathrm{COOH}$ terminus of the predicted $e n v$ gene product was used to identify the products. This antiserum detected a protein of 62 kilodaltons in HTLVproducing cell lines [17, 18] (Fig. 3). When the cell lines were pretreated with tunicamycin, the same antiserum detected 46 kilodaltons protein as a major band instead of 62 kilodaltons. These results indicate that the env gene product is 46 kilodaltons which is then glycosylated into gp62. To test the possible processing of gp62, the pulse-labeled (lane e) cells were chased with cold cysteine (lane f). Antiserum against the peptide now detected a protein of 20 kilodaltons. Thus, the $\mathrm{COOH}$ terminal portion of gp62 was processed into 20 kilodaltons protein (p20E) [18].

For detection of the other matured env gene product derived from the $\mathrm{NH}_{2}$ terminal half of gp62, we produced a hybrid protein composed of the env polypeptide and $\beta$-galactosidase in Escherichia coli as follows. Two fragments of HTLV env gene were inserted into expression vectors pORF1 and pORF2, respectively [19]. $E$. coli transformed with these plasmids produced new proteins with expected sizes as much as $10 \%-20 \%$ of the total proteins [20]. The hybrid proteins produced were found to cross-react with sera from ATL patients, indicating that these hybrid proteins con- 
served antigenic sites in the native env gene products. Using antiserum against these env $\beta$-galactosidases, two diffuse bands of gp46 and gp62 were identified as env gene products [18]. In summary, the env gene codes for 46 kilodaltons precursor which is glycosylated into gp62, and the gp62 is further processed into gp46 and $\mathrm{p} 20 \mathrm{E}$. The proteins so far identified and the gene locations are summarized in Fig. 1 [17, 18].

Finally, we have recently established an EIA system for diagnosis of HTLV infection, detecting env-specific antibodies in human sera [20]. Since these hybrid proteins can be produced on a large scale and are free from any possible contamination by human proteins, the system should be widely useful.

\section{References}

1. Uchiyama T, Yodoi J, Sagawa K, Takatsuki K, Uchino H (1977) Blood 50:481-492

2. Hinuma $Y$, Nagata $K$, Hanaoka $M$, Nakai M, Matsumoto T, Kinoshita K, Shirakawa S, Miyoshi I (1981) Proc Natl Acad Sci USA 78:6476-6480

3. Blattner WA, Kalyanaraman VS, RobertGuroff M, Lister TA, Galton DAG, Sarin PS, Crawford MH, Catovsky D, Greeves M, Gallo RC (1982) Int J Cancer 30:257-264

4. Poiesz BJ, Ruscetti FW, Gazdar AF, Bunn PA, Minna JD, Gallo RC (1980) Proc Natl Acad Sci USA 77:7415-7419

5. Yoshida M, Miyoshi I, Hinuma Y (1982) Proc Natl Acad Sci USA 79:2031-2035
6. Seiki M, Hattori S, Yoshida M (1982) Proc Natl Acad Sci USA 79:6899-6902

7. Seiki M, Hattori S, Hirayama Y, Yoshida M (1983) Proc Natl Acad Sci USA 80:3618 $-3622$

8. Watanabe T, Seiki M, Yóshida M (1983) Science 222:1178

9. Watanabe T, Seiki M, Yoshida M (1984) Virology 133:238-241

10. Reitz MS, Poiesz BJ, Ruscetti FM, Gallo RC (1981) Proc Natl Acad Sci USA 78: 1887-1891

11. Kalyanaraman VS, Sarngadhara MG, Nakao Y, Ito Y, Aoki T, Gallo RC (1982) Proc Natl Acad Sci USA 79: 1653-1657

12. Yoshida M, Seiki M, Yamaguchi K, Takatsuki K (1984) Proc Natl Acad Sci USA 81: 2534-2537

13. Yoshida M, Seiki M, Hattori S, Watanabe T (1984) In: Gallo RC, Essex ME, Grass L (eds) Human T-cell leukemia-lymphoma viruses. Cold Spring Harbor Laboratory, New York, pp 141-148

14. Yoshida M (1983) Gann 74:777-789

15. Hayward WS, Neel BG, Astrin SM (1981) Nature 290:475-480

16. Seiki M, Eddy R, Shows RB, Yoshida $M$ (1984) Nature 309:640-642

17. Hattori S, Imagawa $K$, Shimizu $F$, Hashimura E, Seiki M, Yoshida M (1983) Gann 74:790-793

18. Hattori $S$, Kiyokawa T, Imagawa $K$, Shimizu F, Hashimura E, Seiki M, Yoshida M (1984) Virology 136:338-347

19. Weinstock GM, AP Rhys C, Berman ML, Hampar E, Jackson D, Silhavy TJ, Weisemann J, Zweig M (1983) Proc Natl Acad Sci USA 80:4432-4436

20. Kiyokawa T, Hattori S, Seiki M, Yoshida M (1984) Proc Natl Acad Sci USA 81:6202-6206 